Check for updates

Cite this: RSC Adv., 2018, 8, 19341

Received 9th April 2018

Accepted 20th May 2018

DOI: $10.1039 / c 8 r a 03025 a$

rsc.li/rsc-advances

\section{Synthesis, aggregation induced emission and through space conjugation of triphenylvinylphenyl substituted [2.2]paracyclophane-1,9-diene $\uparrow$}

\begin{abstract}
Chin-Yang Yu (D)* and Yu-Chun Lai
4-Bromo substituted [2.2]paracyclophane-1,9-diene was synthesized from the corresponding dithia[3.3] paracyclophane in three steps through benzyne Steven rearrangement, oxidation, and a thermal elimination reaction. 4-Triphenylvinylphenyl substituted [2.2]paracyclophane-1,9-diene was successfully prepared by the Suzuki-Miyaura cross-coupling reaction of 4-bromo substituted [2.2]paracyclophane1,9-diene and 4,4,5,5-tetramethyl-2-(4-(1,2,2-triphenylvinyl)phenyl)-1,3,2-dioxaborolane using $\mathrm{Pd}(\mathrm{OAc})_{2}$ as a catalyst, $S$-Phos as a ligand and $\mathrm{K}_{3} \mathrm{PO}_{4}$ as a base. The structures of bromo substituted [2.2] paracyclophane-1,9-diene and triphenylvinylphenyl substituted [2.2] paracyclophane-1,9-diene were fully characterized by ${ }^{1} \mathrm{H}$ NMR spectroscopy and X-ray crystallography. 4-Triphenylvinylphenyl substituted [2.2] paracyclophane-1,9-diene exhibited aggregation-induced emission characteristics when the water fraction was higher than $80 \%$ in the THF/water mixtures. 4-Triphenylvinylphenyl substituted [2.2] paracyclophane-1,9-diene displays much higher fluorescence when the water fraction is $90 \%$ compared to that of model compounds due to both through bond and through space conjugation. To the best for our knowledge, we are the first to synthesize triphenylvinylphenyl substituted [2.2] paracyclophane-1,9diene with aggregation-induced emission characteristics.
\end{abstract}

\section{Introduction}

[2.2]Paracyclophanes have received tremendous attention over the past six decades. ${ }^{\mathbf{1 - 5}}$ The structures of [2.2]paracyclophanes which comprise intramolecular face-to-face $\pi$-conjugated phenyl rings give rise to unique electronic and optical properties. $^{3,6}$ The introduction of substituents onto the individual phenyl rings of [2.2]paracyclophanes makes them become chiral molecules that were widely used as the building blocks for organic reactions and catalyst applications. ${ }^{7-9}$ Recently, a number of conjugated molecules bonded to the two individual phenyl rings of the [2.2]paracyclophanes have been intensively prepared and investigated. ${ }^{\mathbf{1 0 - 1 2}}$ These types of substituted [2.2] paracyclophanes exhibited remarkable intramolecular through space conjugation and charge transfer features which lead to potential applications in optoelectronics.

[2.2] Paracyclophane-1,9-dienes were first synthesized by Dewhirst and Cram in the 1960s. ${ }^{13}$ [2.2]Paracyclophanedienes are one of the paracyclophene families in which the two bridges

Department of Materials Science and Engineering, National Taiwan University of Science and Technology, 43, Section 4, Keelung Road, Taipei, 10607, Taiwan. E-mail: cyyu@mail.ntust.edu.tw

$\dagger$ Electronic supplementary information (ESI) available: the synthesis of starting materials for compound 1 and X-ray crystallographic data. CCDC 1830878 (TPE-PCPDE) and 1833417 (Br-PCPDE). For ESI and crystallographic data in CIF or other electronic format see DOI: 10.1039/c8ra03025a are replaced by cis-vinylenes that increase the angles between the bridgehead carbons and the other central carbons of the phenyl rings. Therefore, the highly twisted, ring strained nature with cis-vinylene bridges of [2.2]paracyclophanedienes makes them enable to be ring-opened by carbene initiator to form phenylenevinylenes. ${ }^{\mathbf{1 4 - 1 7}}$ The alkoxy or alkyl substituted paracyclophanedienes and their soluble phenylenevinylene homopolymers and block copolymers prepared by direct ring-opening metathesis polymerization (ROMP) have been reported..$^{18-22}$ In addition, a variety of phanedienes, phanetrienes or phanetetraenes have been synthesized and investigated. ${ }^{23-25}$ One of the advantages for soluble phenylenevinylene polymers by ROMP of alkoxy or alkyl substituted paracyclophanedienes is that the precise control of the molecular weights, polydispersity index (PDI) as well as the functional end groups as this give low defect structures of the polymers.

In general, most of the conjugated small molecules showed significant fluorescence quenching in the aggregate state due to strong intermolecular interaction. The aggregation-caused quenching (ACQ) effect therefore limits the uses of conjugated molecules in aqueous solution or in solid state. This issue can be solved after the aggregation induced emission (AIE) phenomenon was first discovered by Tang and co-workers. ${ }^{26}$ After that, the AIE active molecules have been intensively prepared. In particular, tetraphenylethenes (TPE) with propeller-like structures have attracted much attention possibly due to the facile preparation and purification. The TPE and its 
derivatives have been intensively investigated and widely used as sensors for the detection of a variety of analysts ${ }^{27-29}$ owing to high luminescence efficiency and good photostability.

Herein, we reported the synthesis of 4-triphenylvinylphenyl substituted [2.2]paracyclophane-1,9-diene (TPE-PCPDE) by Suzuki-Miyaura cross-coupling reaction of 4-bromo substituted [2.2]paracyclophane-1,9-diene and 4,4,5,5-tetramethyl-2-(4(1,2,2-triphenylvinyl)phenyl)-1,3,2-dioxaborolane using $\mathrm{Pd}(\mathrm{OAc})_{2}$ as a catalyst, $S$-Phos as a ligand and $\mathrm{K}_{3} \mathrm{PO}_{4}$ as a base. The structural characterization, optical properties as well as the aggregation-induced emission characteristics of TPE-PCPDE compared to the model compounds such as paracyclophanediene (PCPDE), tetraphenylethene (TPE) and phenyl substituted tetraphenylethene (P-TPE) were investigated. The structure of triphenylvinylphenyl substituted paracyclophanediene TPE-PCPDE and the model compounds such as PCPDE, TPE and P-TPE is shown in Fig. 1.

\section{Experimental}

\section{Materials and instrumentation}

All reagents were from commercial sources and were used without further purification. Solvents used for spectroscopic measurements were spectrograde. Most of the reactions were monitored by thin-layer chromatography carried out on silica gel plates. Preparative separations were performed by column chromatography on silica gel grade $60(0.040-0.063 \mathrm{~mm})$ from Merck. The starting material, dithiaparacyclophane 1, was synthesized by the modification of previously established synthetic methods (more details see ESI $\dagger$ ). Nuclear magnetic resonance (NMR) spectra were obtained on a Bruker ultrashield spectrometer operating at $600 \mathrm{MHz}$ for ${ }^{1} \mathrm{H}$ nuclei and $150 \mathrm{MHz}$ for ${ }^{13} \mathrm{C}$ nuclei. Chemical shifts are reported in ppm. All coupling constants are reported in hertz $(\mathrm{Hz})$. The abbreviations are used to indicate multiplicity: $\mathrm{s}=$ singlet, $\mathrm{d}=$ doublet, $\mathrm{dd}=$ doublet of doublets, $\mathrm{t}=$ triplet and $\mathrm{m}=$ multiplet. UV-vis absorption and photoluminescence spectra were recorded on the Jasco ( $\mathrm{V}$ -670) UV-Vis-NIR spectrophotometer and on the Jasco (FP8500) fluorescence spectrophotometer, respectively. X-ray crystallographic data for single crystals were determined using a Bruker Kappa APEX II diffractometer equipped with an Oxford Cryosystems 700 series cryostream cooler using graphite monochromated Mo-K $\alpha$ radiation. Electron impact mass spectra (EIMS) were recorded on a JEOL JMS-700 spectrometer. The melting point of compounds were recorded on a MEL-TEMP 1001D capillary melting point apparatus without further calibration. In order to model the electron affinity and ionization

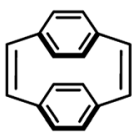

PCPDE

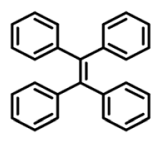

TPE

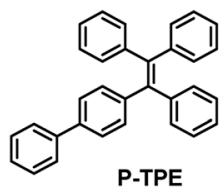

P-TPE

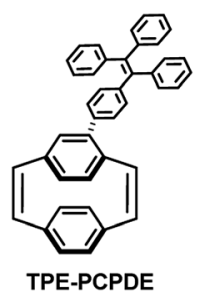

TPE-PCPDE

Fig. 1 The structure of PCPDE, TPE, P-PCPDE and TPE-PCPDE. potential, the HOMO and LUMO of PCPDE, TPE, P-TPE and TPE-PCPDE were computed using density functional theory. Becke's three parameter exchange and the Lee-Young-Parry correlation functionals (B3LYP) were used with added polarization basis functions $\left(6-31 \mathrm{G}^{*}\right)$.

\section{Syntheses}

Synthesis of bis(sulfoxide) compounds 2 . To a boiling solution of 1 (4.22 g, $12 \mathrm{mmol}$ ) and anthranilic acid (5.75 g, 42 $\mathrm{mmol}$ ) in anhydrous 1,2-dichloroethane (300 $\mathrm{mL})$, isoamyl nitrite $(6.6 \mathrm{~mL}, 49 \mathrm{mmol})$ was added dropwise for at least 30 minutes. The resulting solution was stirred under reflux for an additional 30 minutes. After evaporating the solvent, the residue was transferred to a silica gel column, using hexane following by DCM : hexane $(3: 7)$ as eluents. The main fraction was collected to give bis(sulfide) compounds as the yellow oils in a yield of $74 \%$. Bis(sulfide) compounds were very difficult to characterize by NMR spectroscopy due to the large numbers of overlapping signals. HRMS (EI, $\left.\mathbf{M}^{+}\right)$: calculated for $\left[\mathrm{C}_{28} \mathrm{H}_{23} \mathrm{BrS}_{2}\right]^{+}: m / z$ 502.0425, found $m / z$ 502.0425. Hydrogen peroxide $(1.07 \mathrm{~mL}, 35 \mathrm{wt} \%)$ was added dropwise to the solution of bis(sulfide) compounds (3.1 g, $6.16 \mathrm{mmol}$ ) in toluene (145 $\mathrm{mL})$ and acetic acid $(48 \mathrm{~mL})$ over a period of 30 minutes at $0{ }^{\circ} \mathrm{C}$. The solution was allowed to warm up to room temperature and kept stirring for another 12 hours. The resulting solution was extracted with DCM and brine, dried with anhydrous $\mathrm{MgSO}_{4}$ and concentrated to give compound 2 as yellow oils in a yield of $93 \%$ without further purification. Again, the ${ }^{1} \mathrm{H}$ NMR spectrum of compound 2 exhibited a complex range of signals and characterization was not possible. HRMS (EI, $\mathrm{M}^{+}$): calculated for $\left[\mathrm{C}_{28} \mathrm{H}_{23} \mathrm{BrO}_{2} \mathrm{~S}_{2}\right]^{+}: m / z 534.0323$, found $m / z 534.0320$ (see Fig. S21 in $\mathrm{ESI} \dagger$ ).

Synthesis of 4-bromo-[2.2] paracyclophane-1,9-diene (BrPCPDE). A solution of $2(3.08 \mathrm{~g}, 5.75 \mathrm{mmol})$ in $p$-xylene $(190 \mathrm{~mL})$ was refluxed under an argon steam for 20 hours. After removing the solvent, the residue was chromatographed over silica gel using hexane as an eluent. The compound was further purified by recrystallization to give compound Br-PCPDE as white solids with the yield of $16 \% .{ }^{1} \mathrm{H}$ NMR $\left(600 \mathrm{MHz}, \mathrm{CDCl}_{3}, \delta\right): 7.24(\mathrm{~d}, J=$ $10.2 \mathrm{~Hz}, 1 \mathrm{H}, \mathrm{ArCH}=\mathrm{CH}-), 7.19(\mathrm{~d}, J=10.2 \mathrm{~Hz}, 1 \mathrm{H}, \mathrm{ArCH}=\mathrm{CH}-$ ), $7.10(\mathrm{~d}, J=10.2 \mathrm{~Hz}, 1 \mathrm{H}, \mathrm{ArCH}=\mathrm{CH}-), 7.07$ (d, $J=7.8 \mathrm{~Hz}, 1 \mathrm{H}$, $\mathrm{ArH}), 6.93$ (d, $\left.J=10.2 \mathrm{~Hz}, 1 \mathrm{H}, \mathrm{ArCH}=\mathrm{CH}^{-}\right), 6.66$ (s, 1H, $\operatorname{ArH}$ ), $6.64(\mathrm{~d}, J=7.8 \mathrm{~Hz}, 1 \mathrm{H}, \mathrm{ArH}), 6.56$ (d, $J=7.8 \mathrm{~Hz}, 1 \mathrm{H}, \operatorname{ArH}), 6.47$ $(\mathrm{d}, J=7.8 \mathrm{~Hz}, 2 \mathrm{H}, \mathrm{ArH}), 6.41(\mathrm{~d}, J=7.8 \mathrm{~Hz}, 1 \mathrm{H}, \mathrm{ArH}) .{ }^{13} \mathrm{C} \mathrm{NMR}$ $\left(150 \mathrm{MHz}, \mathrm{CDCl}_{3}, \delta\right): \delta$ 139.99, 138.08, 138.05, 137.94, 137.59, 136.48, 136.42, 135.75, 135.69, 133.09, 131.67, 130.75, 130.47, 130.40, 126.71, 124.44. HRMS (EI, $\left.\mathrm{M}^{+}\right)$: calculated for $\left[\mathrm{C}_{16} \mathrm{H}_{11} \mathrm{Br}\right]^{+}: m / z 282.0044$, found $m / z 282.0044$ (see Fig. S22 in ESI†). Mp: $135^{\circ} \mathrm{C}$.

Synthesis of 4-(4-(1,2,2-triphenylvinyl)phenyl)-[2.2] paracyclophane-1,9-diene (TPE-PCPDE). A mixture of 4-bromo[2.2]paracyclophane-1,9-diene Br-PCPDE (56.6 mg, $0.2 \mathrm{mmol}$ ), 4,4,5,5-tetramethyl-2-(4-(1,2,2-triphenylvinyl)phenyl)-1,3,2dioxaborolane (110 mg, $0.24 \mathrm{mmol}), \mathrm{Pd}(\mathrm{OAc})_{2}$ (4.5 mg, 0.02 mmol) and $S$-Phos (16.4 $\mathrm{mg}, 0.04 \mathrm{mmol}$ ) were charged into a Schlenk tube under an argon atmosphere. Deoxygenated THF 
$(2.0 \mathrm{~mL})$ and $2.0 \mathrm{M}$ aqueous $\mathrm{K}_{3} \mathrm{PO}_{4}(0.67 \mathrm{~mL})$ were added to the reaction mixture and then the reaction mixture was heated to reflux for 72 hours. After filtrating the insoluble solid and removing most of the solvent, the residue was extracted with DCM and brine several times, dried with anhydrous $\mathrm{MgSO}_{4}$ and removed the solvent. The crude compound was purified by column chromatography (DCM : hexane, $1: 9(\mathrm{v} / \mathrm{v})$ ) to give compound TPE-PCPDE as white solids in a yield of $81 \% .{ }^{1} \mathrm{H}$ NMR (600 MHz, $\mathrm{CDCl}_{3}, \delta$ ): $7.25(\mathrm{~d}, J=10.5 \mathrm{~Hz}, 1 \mathrm{H}, \mathrm{ArCH}=\mathrm{CH}-$

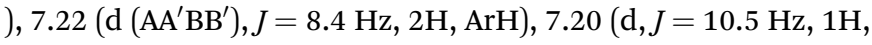
$\mathrm{ArCH}=\mathrm{CH}-), 7.14$ (d, $J=10.5 \mathrm{~Hz}, 1 \mathrm{H}, \mathrm{ArCH}=\mathrm{CH}-), 7.18-7.04$ $(\mathrm{m}, 16 \mathrm{H}, \operatorname{ArH}), 6.90$ (d, $J=10.5 \mathrm{~Hz}, 1 \mathrm{H}, \mathrm{ArCH}=\mathrm{CH}-), 6.72(\mathrm{~s}$, $1 \mathrm{H}, \operatorname{ArH}), 6.65(\mathrm{~d}, J=8.1 \mathrm{~Hz}, 1 \mathrm{H}, \operatorname{ArH}), 6.56(\mathrm{~d}, J=8.1 \mathrm{~Hz}, 1 \mathrm{H}$, ArH), 6.51 (d, $J=7.8 \mathrm{~Hz}, 1 \mathrm{H}, \mathrm{ArH}), 6.47$ (d (A2), $J=7.8 \mathrm{~Hz}, 2 \mathrm{H}$, $\mathrm{ArH}), 6.36$ (d, $J=7.8 \mathrm{~Hz}, 1 \mathrm{H}, \mathrm{ArH}) .{ }^{13} \mathrm{C} \mathrm{NMR}\left(150 \mathrm{MHz}, \mathrm{CDCl}_{3}\right.$, $\delta): 143.92,143.81,143.62,142.63,141.39,141.26,140.88,138.62$, $138.48,138.22$, 137.81, 137.29, 137.00, 136.07, 134.57, 133.31, $131.60,131.55,131.51,131.50,131.12,130.74,130.54,130.51$, 129.33, 128.66, 127.84, 127.79, 127.76, 127.32, 126.63, 126.58, 126.56, 138.24. HRMS $\left(\mathrm{EI}, \mathrm{M}^{+}\right)$: calculated for $\left[\mathrm{C}_{42} \mathrm{H}_{30}\right]^{+}: \mathrm{m} / z$ 534.2348 , found $m / z 534.2345$ (see Fig. S23 in ESI $\dagger$ ). Mp: $143{ }^{\circ} \mathrm{C}$.

\section{Results and discussion}

The routes to synthesize 4-triphenylvinylphenyl-[2.2] paracyclophane-1,9-diene are shown in Scheme 1. The starting material, dithiaparacyclophane 1 (see ESI $\dagger$ ), was prepared by the cyclization of an equimolar amount of 2-bromo-1,4bis(bromomethyl)benzene S2 and 1,4-phenylenedimethanethiol $\mathbf{S 4}$ under a high dilution in the presence of aqueous potassium hydroxide for at least 3 days to avoid the formation of oligomers and polymers.

Compound 2 was prepared by the benzyne induced Stevens rearrangement using anthranilic acid and isoamyl nitrite following by oxidation using $\mathrm{H}_{2} \mathrm{O}_{2}$ (35 wt\%). ${ }^{30,31}$ Compound 2 was then obtained as semi-solids in an overall yield of $68 \%$. Compound 2 was then dissolved in $p$-xylene at reflux under an argon atmosphere for 20 hours. The 4-bromo-[2.2]paracyclophane-1,9-diene (Br-PCPDE)

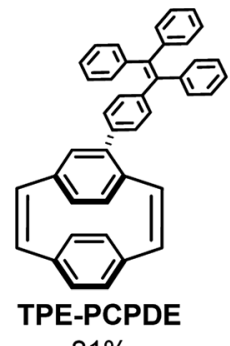

$81 \%$

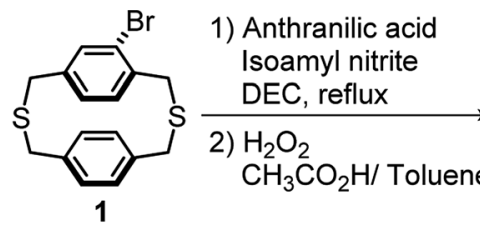

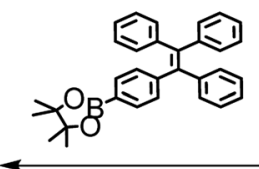

$\mathrm{Pd}(\mathrm{OAc})_{2} / \mathrm{S}-\mathrm{Phos}$ $2 \mathrm{M} \mathrm{K}_{3} \mathrm{PO}_{4}$ (aq) THF, reflux

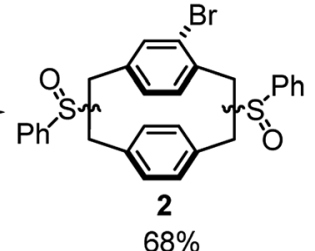
$p$-Xylene, reflux

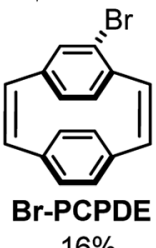
$16 \%$
Scheme 1 Synthetic route to triphenylvinylphenyl substituted [2.2] paracyclophane-1,9-diene (TPE-PCPDE). was obtained in a yield of $16 \%$ after purification by column chromatography and recrystallization. The 4-triphenylvinylphenyl substituted [2.2]paracyclophane-1,9-diene (TPE-PCPDE) was synthesized by the reaction of Br-PCPDE and 4,4,5,5-tetramethyl-2(4-(1,2,2-triphenylvinyl)phenyl)-1,3,2-dioxaborolane in the presence of $\mathrm{Pd}(\mathrm{OAc})_{2}$ and 2-dicyclohexylphosphino-2',6'-dimethoxybiphenyl ( $S$-Phos) in THF and aqueous $\mathrm{K}_{3} \mathrm{PO}_{4}$ at reflux for 72 hours. After purified by column chromatography, the TPE-PCPDE was obtained in a yield of $81 \%$.

The ${ }^{1} \mathrm{H}$ NMR spectrum of Br-PCPDE in $\mathrm{CDCl}_{3}$ is shown in Fig. 2a. The four doublets $(7.24,7.19,7.10$ and $6.93 \mathrm{ppm}$, each $J=10.2 \mathrm{~Hz}, 1 \mathrm{H})$ were assigned to the cis-vinylic hydrogens. Two doublets at 7.07 and $6.41 \mathrm{ppm}$ with $J=7.8 \mathrm{~Hz}$ were associated with the hydrogens of non-substituted phenyl ring. In addition, the doublet at $6.47 \mathrm{ppm}(J=7.8 \mathrm{~Hz})$ integrating to two hydrogens corresponds to the hydrogens to the non-substituted phenyl ring. A singlet at $6.66 \mathrm{ppm}$ corresponds to the aromatic hydrogen at the ortho-position to the bromine atom. The two doublets (6.64 and $6.56 \mathrm{ppm}$, each $J=7.8 \mathrm{~Hz}, 1 \mathrm{H}$ ) were assigned to the hydrogens at the para- and meta-positions to the bromine atom, respectively. The ${ }^{1} \mathrm{H}$ NMR spectrum of TPEPCPDE in $\mathrm{CDCl}_{3}$ is shown in Fig. 2b. The two doublets (7.25 and $7.20 \mathrm{ppm}$, each $J=10.5 \mathrm{~Hz}, 1 \mathrm{H}$ ) were assigned to the cis-vinylic hydrogens. In addition, a doublet at $6.90 \mathrm{ppm}(J=10.5 \mathrm{~Hz}, 1 \mathrm{H})$
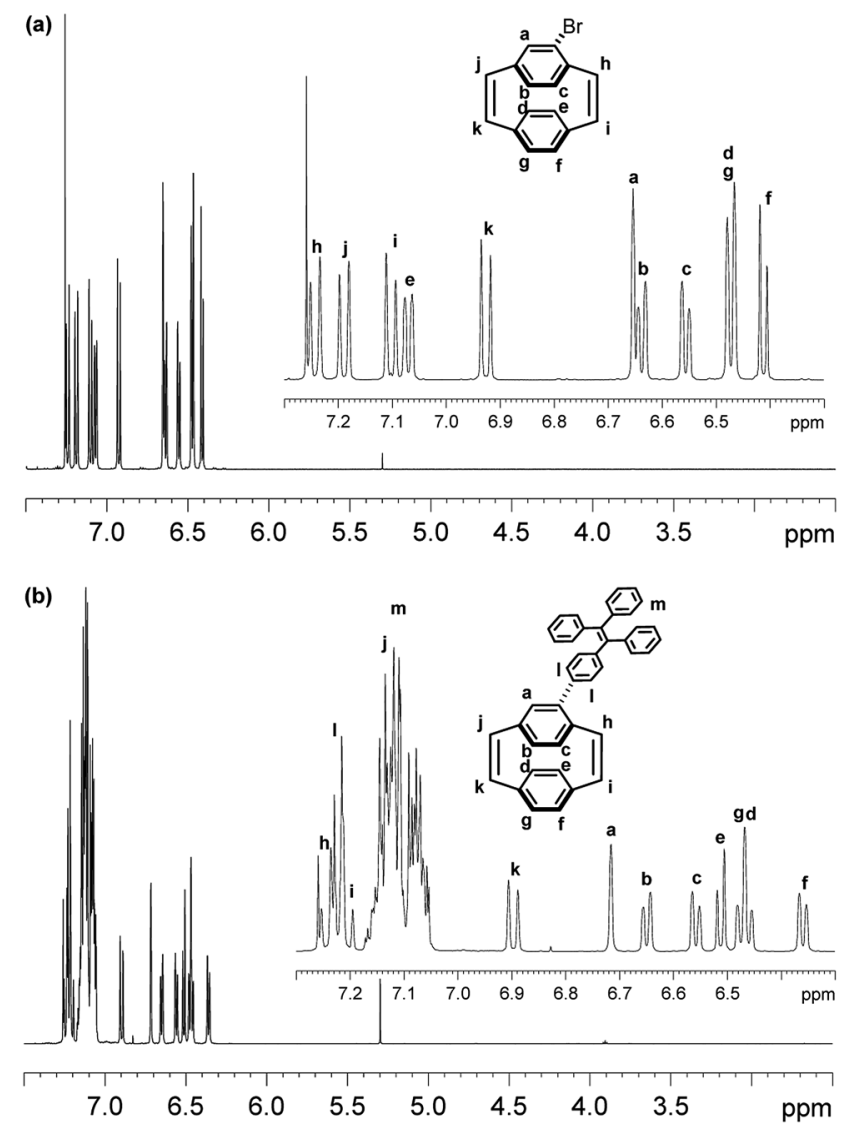

Fig. $2{ }^{1} \mathrm{H}$ NMR spectra of (a) 4-bromo-[2.2] paracyclophane-1,9-diene $\mathrm{Br}-\mathrm{PCPDE}$ and (b) 4-triphenylvinylphenyl-[2.2] paracyclophane-1,9diene TPE-PCPDE in $\mathrm{CDCl}_{3}$. Signals associated with alkenic and aromatic hydrogens are shown in the insets. 
was assigned to the cis-vinylic hydrogen. It should be noted that a doublet at around $7.14 \mathrm{ppm}(J=10.5 \mathrm{~Hz}, 1 \mathrm{H})$ can be assigned to the remaining $c i s$-vinylic hydrogen which is overlapping with the hydrogens of TPE moiety. The doublet at $7.22 \mathrm{ppm}\left(\mathrm{AA}^{\prime} \mathrm{BB}^{\prime}\right.$ system, $J=8.4 \mathrm{~Hz}, 2 \mathrm{H}$ ) corresponds to the hydrogens to the ortho position bonded to the carbon of the PCPDE. The multiple between 7.18 and $7.04 \mathrm{ppm}$ represent for the rest of the hydrogens of TPE moiety. A singlet peak at $6.72 \mathrm{ppm}$ and two doublet peaks (6.65 and $6.56 \mathrm{ppm}$, each $J=8.1 \mathrm{~Hz}, 1 \mathrm{H}$ ) were assigned to the aromatic hydrogens at the ortho-, para- and meta-positions to the bromine atom, respectively. The two doublets (6.51 and $6.36 \mathrm{ppm}$, each $J=7.8 \mathrm{~Hz}, 1 \mathrm{H})$ were assigned to hydrogens of the non-substituted phenyl ring. In addition, the two doublet peaks at $6.47 \mathrm{ppm}$ (an A2 system) with $J=$ $7.8 \mathrm{~Hz}$ are two hydrogens belong to the non-substituted phenyl ring. $2 \mathrm{D}^{1} \mathrm{H}-{ }^{1} \mathrm{H}$ COSY can confirm the peak assignment and can be found in ESI. $\dagger$

The single crystal of Br-PCPDE and TPE-PCPDE can be obtained by slow evaporation from a dilute hexane solution at room temperature and the solid-state structure of Br-PCPDE and TPE-PCPDE was determined by X-ray crystallography. For solid-state structure of Br-PCPDE (Fig. 3a), the average vinylene bond length is $1.34 \AA$ which is in agreement with a standard cis-

(a)

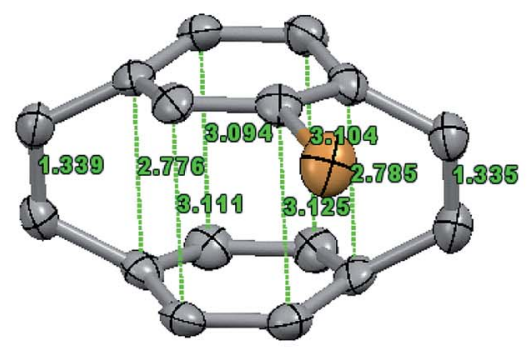

(b)

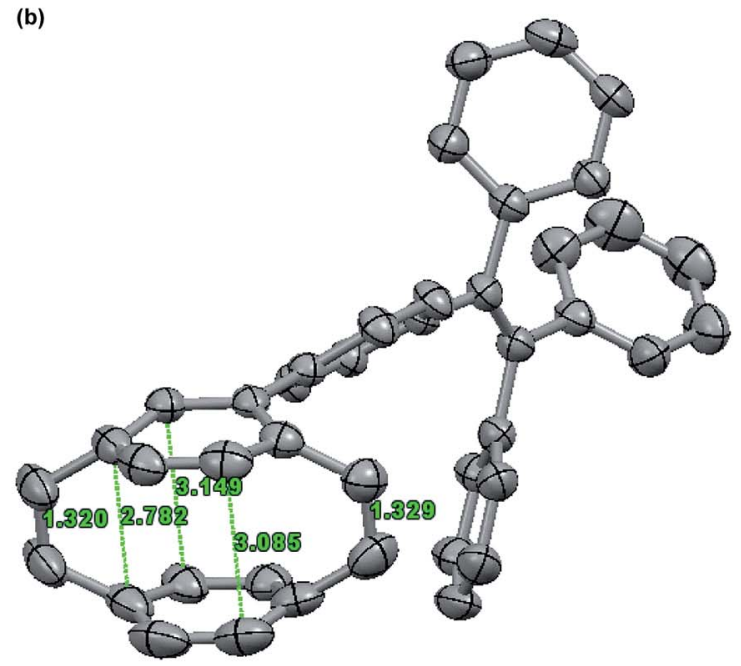

Fig. 3 Solid-state structure of (a) Br-PCPDE and (b) TPE-PCPDE. Hydrogen atoms are omitted for clarity. Thermal ellipsoids are set at $50 \%$ probability. vinylene bond (1.32 ̊). The average intramolecular distance between the two carbons of the phenyl rings bonded to carbons of vinylene is $2.78 \AA$ which is the same value with that of the unsubstituted PCPDE reported previously. The average intramolecular separation between the central carbon atoms of the phenyl rings is $3.11 \AA$ A. The carbons of the phenyl rings bonded to the carbons of vinylene are significantly out of plane of the four central carbons and the average deviation is of around $13.1^{\circ}$. It should be noted that the largest value $\left(13.43^{\circ}\right)$ of out of plane for the carbon which is in the ortho-position relative to the carbon bonded to bromine atom was observed. The average $\mathrm{C}($ aryl $)-\mathrm{C}($ methine) bond length is $1.50 \AA$. The solid-state structure of TPE-PCPDE determined by X-ray crystallography is shown in Fig. 3b. The average bond length of vinylene is 1.32 $\AA$ which is the same value compared to a standard cis-vinylene bond (1.32 ̊). The average intramolecular separation between the central carbon atoms of the phenyl rings is $3.12 \AA$. The average intramolecular distance between the carbon atoms of the phenyl rings linked to carbons of vinylene is significantly shortened to $2.79 \AA$. The dihedral angle between the phenyl rings of PCPDE and TPE moieties is around $39^{\circ}$. The carbons of the phenyl rings connected to the vinylene in PCPDE moieties are significantly out of plane of the four central carbons and the average deviation is of around $13.4^{\circ}$. A large distortion in the phenyl rings can be seen which indicates the highly ring strained nature of this molecule. The average C(aryl)$\mathrm{C}$ (methine) bond length is $1.50 \AA$. Both of the crystal packing structures of compounds Br-PCPDE and TPE-PCPDE (space group: $P 2_{1} / c, Z=4$ ) showed four molecules in one unit cells and two pairs of them are racemic mixtures due to the chirality center of substituted phenyl rings of paracyclophanedienes.

The model compounds PCPDE, TPE and P-TPE were prepared by the modification of established procedures reported previously. ${ }^{32-34}$ The initial concentration of compounds PCPDE, TPE, P-TPE and TPE-PCPDE is $2 \times 10^{-6} \mathrm{M}$ in dilute THF solution in order to eliminate the potential interference of intermolecular interactions. The UV-vis absorption peak of PCPDE, TPE, P-TPE and TPE-PCPDE in dilute THF solution exhibited at 242, 309, 321 and $325 \mathrm{~nm}$, respectively (Fig. 4a). The notably bathochromic shift from PCPDE, TPE, P-TPE to TPEPCPDE can be attributed to the extension of the conjugation. It should be noted that the longest absorption wavelength of TPEPCPDE is red-shifted by $4 \mathrm{~nm}$ compared to that of P-TPE possibly due to the through space conjugation of TPE-PCPDE.

The thin films were prepared by spin-casting a solution of the compounds ( $3 \mathrm{mg} \mathrm{mL}^{-1}$ in toluene) onto glass slides $(2.0 \mathrm{~cm}$ $\times 2.0 \mathrm{~cm}$ ) at a rotation speed of $1500 \mathrm{rpm}$ for 20 seconds and then $3000 \mathrm{rpm}$ for 20 seconds. The normalized solid state UV-vis absorption spectra of PCPDE, TPE, P-TPE and TPE-PCPDE were shown in Fig. 4b. The solid state UV-vis absorption maximum of PCPDE, TPE, P-TPE and TPE-PCPDE is at 292, 326, 331 and $335 \mathrm{~nm}$, respectively which shows bathochromic shifts compared to that of solution due to the relatively strong intermolecular interaction in solid state. The details of optical properties of PCPDE, TPE, P-TPE and TPE-PCPDE are summarized in Table 1. 
(a)

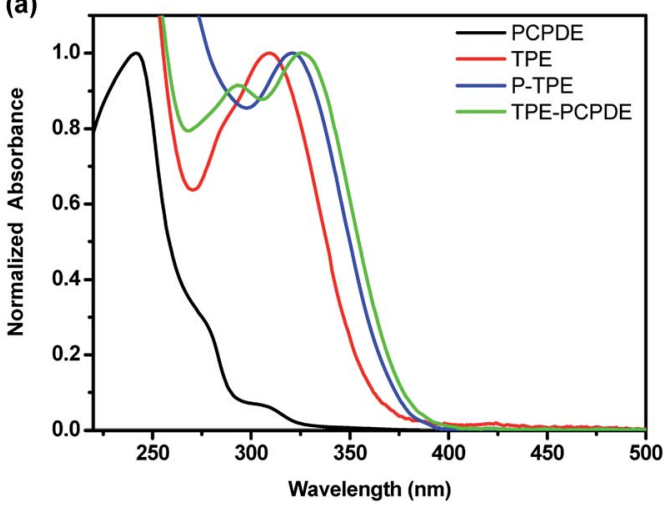

(b)

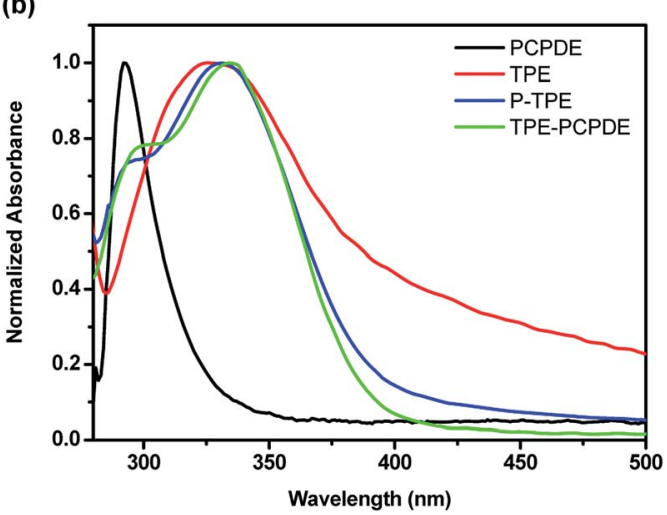

Fig. 4 Normalized (a) solution and (b) solid state UV-vis absorption spectra of PCPDE, TPE, P-TPE and TPE-PCPDE. (The initial concentration for solution is $2 \times 10^{-6} \mathrm{M}$ ).

Again, an absorption maximum of TPE-PCPDE in solid state exhibited a bathochromic shift compared to the model compounds due to the through bond and through space conjugation. It should be noted that the solid state UV-vis absorption spectrum of TPE exhibited a very long tail extending through the whole visible region possibly due to the scattering effect as the quality of films of TPE is poor. In addition, the comparative HOMO and LUMO structures and levels of PCPDE, TPE, P-TPE and TPE-PCPDE using density functional theory calculation (B3LYP functional, 6-31G* basis set) were shown in ESI (Fig. S27 and Table S1 $\dagger$ ). The HOMO levels and LUMO levels became upper and lower, respectively on going from PCPDE, TPE, P-TPE to TPE-PCPDE. Based on the experimental measurements and theoretical calculations, the through bond and through space conjugation make significant

Table 1 Optical properties of PCPDE, TPE, P-TPE and TPE-PCPDE

\begin{tabular}{lllll}
\hline Compound & $\lambda_{\max }{ }^{a}(\mathrm{~nm})$ & $\mathrm{PL}_{\max }{ }^{a}(\mathrm{~nm})$ & $\lambda_{\max }{ }^{b}(\mathrm{~nm})$ & $\mathrm{PL}_{\max }{ }^{b}(\mathrm{~nm})$ \\
\hline PCPDE & 242 & $-c$ & 292 & 379 \\
TPE & 309 & 375 & 326 & 440 \\
P-TPE & 321 & 384 & 331 & 475 \\
TPE-PCPDE & 325 & 416 & 335 & 477
\end{tabular}

${ }^{a}$ In dilute THF $\left(2 \times 10^{-6} \mathrm{M}\right) .{ }^{b}$ In solid state. ${ }^{c}$ Intensity of the signals comparable to spectral noise. contributions to the absorption wavelength and bandgap in TPE-PCPDE when compared with PCPDE, TPE and P-TPE.

The emission spectra of TPE-PCPDE with different water fractions $\left(f_{\mathrm{w}}\right)$ in THF are shown in Fig. 5a. The maximum emission intensity of TPE-PCPDE is very low with little change when the water fraction is lower than $80 \%$. However, the maximum emission intensity of TPE-PCPDE shows significant increase when the water fraction is higher than $80 \%$. This indicates that the TPE-PCPDE exhibited aggregation-induced emission characteristics in THF/water mixtures when the water fraction is higher than $80 \%$. The maximum emission wavelength of TPE-PCPDE is at $475 \mathrm{~nm}$ in its most aggregated state. The pictures of TPE-PCPDE in THF with different water contents under the UV lamp irradiation with a wavelength of $365 \mathrm{~nm}$ are shown in Fig. 5b. Clearly, the TPE-PCPDE in pure THF solution and lower water contents $(<80 \%$ of water $)$ showed very weak fluorescence. In addition, the fluorescence can be seen by naked eyes for TPE-PCPDE when the water fraction is higher than $80 \%$ in the $\mathrm{THF} /$ water mixture.

The photoluminescence quantum yields of TPE, P-TPE to TPE-PCPDE with different water fractions are shown in Fig. 6a. The maximum photoluminescence quantum yield of TPE, PTPE and TPE-PCPDE is $0.049,0.140$ and 0.266 , respectively when the water fraction is $90 \%$ compared to quinine sulfate (0.546) in $0.1 \mathrm{M} \mathrm{H}_{2} \mathrm{SO}_{4}$. TPE is a typical AIE molecule. However, the quantum yield of TPE in $90 \%$ water content reported here was only about $5 \%$ compared to $14-18 \%$ reported previously. This is due to the low initial concentration used in this experiment $\left(2 \times 10^{-6} \mathrm{M}\right)$ which is more than 5 times diluted than reported in previous literatures. ${ }^{35,36}$ Clearly, compound TPEPCPDE displays much higher fluorescence when the water

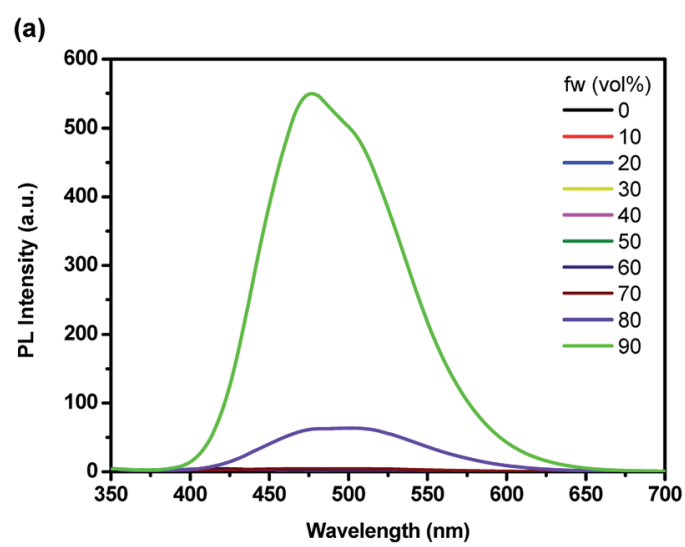

(b)

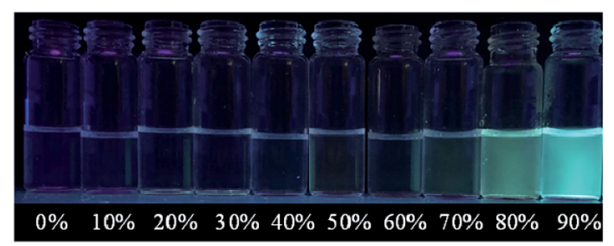

Fig. 5 (a) Photoluminescence spectra of TPE-PCPDE in THF/water mixtures with different water fractions (initial concentration: $2 \times 10^{-6}$ $M$ ) and (b) the pictures of TPE-PCPDE in THF with different water contents under the UV lamp at a wavelength of $365 \mathrm{~nm}$. 


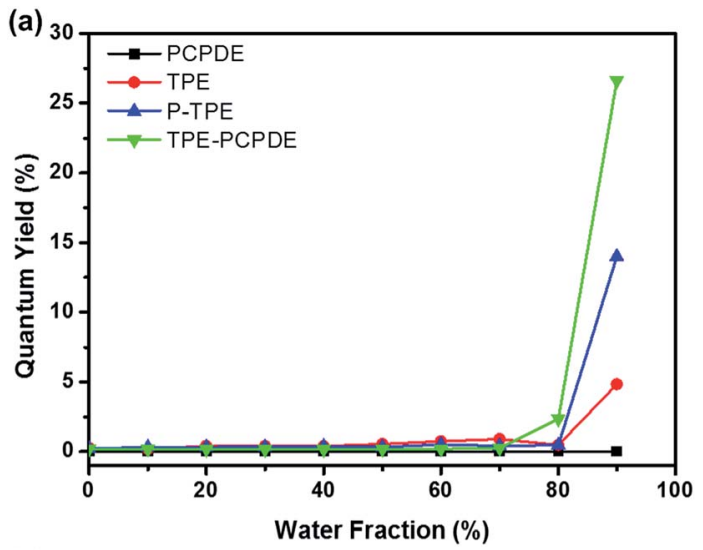

(b)

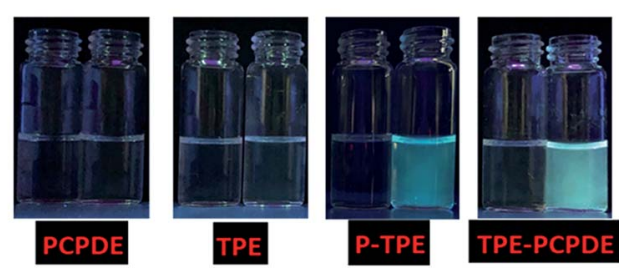

Fig. 6 (a) Plots of photoluminescence quantum yields of PCPDE, TPE, P-TPE and TPE-PCPDE versus water fraction and (b) the pictures of PCPDE, TPE, P-TPE and TPE-PCPDE in THF and in 90\% water/THF mixture under the UV lamp at a wavelength at $365 \mathrm{~nm}$.

fraction is $90 \%$ compared to that of TPE and P-TPE molecules. This indicates that through bond and through space conjugation of TPE-PCPDE which leads to a higher fluorescence than that of TPE and P-TPE. The pictures of PCPDE, TPE, P-TPE and TPE-PCPDE in THF and in 90\% water fraction of the THF/water mixture under the UV lamp at a wavelength at $365 \mathrm{~nm}$ are shown in Fig. 6b. The notable fluorescence can be seen by naked eyes for P-TPE and TPE-PCPDE when the water fraction is 90\% in the THF/water mixture. No fluorescence for PCPDE and very little fluorescence for TPE can be seen by naked eyes.

\section{Conclusions}

Br-PCPDE was synthesized from the corresponding dithia[3.3] paracyclophane in three steps through benzyne Steven rearrangement, oxidation and thermal elimination reaction. TPE-PCPDE was successfully synthesized by the reaction of Br-PCPDE and monoboronic ester substituted tetraphenylethene using $\mathrm{Pd}(\mathrm{OAc})_{2}$ as a catalyst, $S$-Phos as a ligand and $\mathrm{K}_{3} \mathrm{PO}_{4}$ as a base. Functionalized paracyclophanedienes were fully characterized by nuclear magnetic resonance spectroscopy, high resolution mass spectrometry and X-ray crystallography. The longest absorption wavelength of TPE-PCPDE showed bathochromic shift compared to that of P-TPE due to the through space conjugation. TPE-PCPDE exhibited aggregation-induced emission characteristics when the water fraction was higher than $80 \%$ in the $\mathrm{THF} /$ water mixtures. TPE-PCPDE exhibited high fluorescence when the water fraction is 90\% compared to that of TPE and P-TPE due to the through bond and through space conjugation. The ROMP of TPE-PCPDE by ruthenium carbene initiators is currently under investigation.

\section{Conflicts of interest}

There are no conflicts to declare.

\section{Acknowledgements}

Financial support from the Ministry of Science and Technology and the National Taiwan University of Science and Technology Taiwan is gratefully acknowledged.

\section{Notes and references}

1 C. J. Brown and A. C. Farthing, Nature, 1949, 164, 915-916.

2 S. E. Gibson and J. D. Knight, Org. Biomol. Chem., 2003, 1, 1256-1269.

3 H. Hopf, Angew. Chem., Int. Ed., 2008, 47, 9808-9812.

4 Y. Morisaki and Y. Chujo, Prog. Polym. Sci., 2008, 33, 346364.

5 P. G. Ghasemabadi, T. Yao and G. J. Bodwell, Chem. Soc. Rev., 2015, 44, 6494-6518.

6 E. Elacqua and L. R. MacGillivray, Eur. J. Org. Chem., 2010, 6883-6894.

7 Y. Morisaki, M. Gon, T. Sasamori, N. Tokitoh and Y. Chujo, J. Am. Chem. Soc., 2014, 136, 3350-3353.

8 B. Jiang, Y. Lei and X.-L. Zhao, J. Org. Chem., 2008, 73, 78337836.

9 H. Hinrichs, A. J. Boydston, P. G. Jones, K. Hess, R. Herges, M. M. Haley and H. Hopf, Chem.-Eur. J., 2006, 12, 7103-7115. 10 S. P. Jagtap, S. Mukhopadhyay, V. Coropceanu, G. L. Brizius, J. L. Brédas and D. M. Collard, J. Am. Chem. Soc., 2012, 134, 7176-7185.

11 H. Y. Woo, J. W. Hong, B. Liu, A. Mikhailovsky, D. Korystov and G. C. Bazan, J. Am. Chem. Soc., 2005, 127, 820-821.

12 J. L. Zafra, A. M. Ontoria, P. M. Burrezo, M. Peña-Alvarez, M. Samoc, J. Szeremeta, F. J. Ramírez, M. D. Lovander, C. J. Droske, T. M. Pappenfus, L. Echegoyen, J. T. López Navarrete, N. Martin and J. Casado, J. Am. Chem. Soc., 2017, 139, 3095-3105.

13 K. C. Dewhirst and D. J. Cram, J. Am. Chem. Soc., 1958, 80, 3115-3125.

14 E. Thorn-Csányi, P. Kraxner and J. Hammer, J. Mol. Catal., 1994, 90, 15-20.

15 V. P. Conticello, D. L. Gin and R. H. Grubbs, J. Am. Chem. Soc., 1992, 114, 9708-9710.

16 Y. J. Miao and G. C. Bazan, J. Am. Chem. Soc., 1994, 116, 9379-9380.

17 Y. J. Miao and G. C. Bazan, Macromolecules, 1994, 27, 10631064.

18 C.-Y. Yu and M. L. Turner, Angew. Chem., Int. Ed., 2006, 45, 7797-7800.

19 C.-Y. Yu, M. Horie, A. M. Spring, K. Tremel and M. L. Turner, Macromolecules, 2009, 43, 222-232.

20 C.-Y. Yu, J. W. Kingsley, D. G. Lidzey and M. L. Turner, Macromol. Rapid Commun., 2009, 30, 1889-1892.

21 A. M. Spring, C.-Y. Yu, M. Horie and M. L. Turner, Chem. Commun., 2009, 2676-2678. 
22 B. J. Lidster, D. R. Kumar, A. M. Spring, C.-Y. Yu and M. L. Turner, Polym. Chem., 2016, 7, 5544-5551.

23 C.-Y. Yu, S.-H. Yu, S.-H. Wen and C.-C. Wang, Tetrahedron Lett., 2017, 58, 3854-3858.

24 D. Mäker, C. Maier, K. Brödner and U. H. F. Bunz, ACS Macro Lett., 2014, 3, 415-418.

25 C.-Y. Yu, Y.-C. Chen and C.-C. Wang, New J. Chem., 2017, 41, 14116-14121.

26 J. Luo, Z. Xie, J. W. Y. Lam, L. Cheng, H. Chen, C. Qiu, H. S. Kwok, X. Zhan, Y. Liu, D. Zhu and B. Z. Tang, Chem. Commun., 2001, 381, 1740-1741.

27 Z. Luo, B. Liu, S. Si, Y. Lin, C. S. Luo, C. Pan, C. Zhao and L. Wang, Dyes Pigm., 2017, 143, 463-469.

28 H.-T. Feng, J.-H. Wang and Y.-S. Zheng, ACS Appl. Mater. Interfaces, 2014, 6, 20067-20074.

29 C.-Y. Yu and C.-C. Hsu, Polymer, 2018, 137, 30-37.
30 B. J. Lidster, D. R. Kumar, A. M. Spring, C.-Y. Yu, M. Helliwell, J. Raftery and M. L. Turner, Org. Biomol. Chem., 2016, 14, 6079-6087.

31 C.-Y. Yu, C.-H. Sie and C.-Y. Yang, New J. Chem., 2014, 38, 5003-5008.

32 C.-Y. Yu, M. Helliwell, J. Raftery and M. L. Turner, Chem.Eur. J., 2011, 17, 6991-6997.

33 J. L. Muzyka and M. A. Fox, J. Org. Chem., 1991, 56, 45494552.

34 C. Braun, E. Spuling, N. B. Heine, M. Cakici, M. Nieger and S. Bräse, Adv. Synth. Catal., 2016, 358, 1664-1670.

35 Z. Zhao, S. Chen, X. Shen, F. Mahtab, Y. Yu, P. Lu, J. W. Y. Lam, H. S. Kwok and B. Z. Tang, Chem. Commun., 2010, 46, 686-688.

36 H. Li, J. Wang, J. Z. Sun, R. Hu, A. Qin and B. Z. Tang, Polym. Chem., 2012, 3, 1075-1083. 